\title{
Analysis of strong ground motions to evaluate regional attenuation relationships
}

\author{
Gaetano Zonno and Valentina Montaldo \\ Istituto Nazionale di Geofisica e Vulcanologia, Sezione «Pericolosità e Rischio Sismico», Milano, Italy
}

\begin{abstract}
Italian attenuation relationships at regional scale have been refined using a data set of 322 horizontal components of strong ground motions recorded mainly during the 1997-1998 Umbria-Marche, Central Italy, earthquake sequence. The data set includes records generated by events with local magnitude $\left(M_{L}\right)$ ranging between 4.5 and 5.9 , recorded at rock or soil sites and epicentral distance smaller than $100 \mathrm{~km}$. Through a multiple step regression analysis, we calculated empirical equations for the peak ground acceleration and velocity, the Arias Intensity and for the horizontal components of the 5\% damped velocity pseudo response spectra, corresponding to 14 frequencies ranging from 0.25 to $25 \mathrm{~Hz}$. We compared our results with well known predictive equations, widely used on the national territory for Probabilistic Seismic Hazard Analysis. The results obtained in this study show smaller values for all the analyzed ground motion indicators compared to other predictive equations.
\end{abstract}

Key words ground motion indicators - attenuation relationships - Umbria-Marche area

\section{Introduction}

Attenuation relations are mathematical functions relating a strong motion parameter to parameters characterizing: the earthquake, the propagation medium, local site geology and structure (Campbell, 1985). In conventional ground motion models the earthquake source is represented by the magnitude; the effects of wave propagation from the earthquake source to the site region are specified by a distance; and the effects of the soil conditions by a site category (So-merville, 2000). Accelerometric recordings are used to derive scaling equations that predict earthquake-induced ground motion in a certain

Mailing address: Dr. Gaetano Zonno, Istituto Nazionale di Geofisica e Vulcanologia, Sezione «Pericolosità e Rischio Sismico», Via Bassini 15, 20133 Milano, Italy; e-mail: zonno@mi.ingv.it area starting from a simplified empirical model. Usually attenuation relationships are revised after an earthquake as new data are made available to the scientific community. The most recent scaling law for Italy was published in 1996 by Sabetta and Pugliese, just before the earthquake sequence that hit Central Italy in 1997-1998. The purpose of this study is to generate new attenuation relationships using the strong motion data recorded during that sequence.

The main criticism appointed to attenuation function is that usually regional data sets are statistically not significant, while national or global data sets often include records from very different seismotectonic settings that are not mixable (Decanini et al., 2001). Nevertheless, the amount of records available for the UmbriaMarche area in Central Italy is now sufficiently large to perform statistical analysis at regional scale. As fig. 1 shows, the data used in this study are nearly twice the number of records used by Sabetta and Pugliese (1996) for the whole national territory.

Attenuation relationships are used to estimate the pertinent characteristics of real ground motion, 
such as amplitude, frequency content and duration. Several ground motion parameters have been proposed to quantify these characteristics, among which we used peak ground acceleration and velocity to describe amplitude, response spectra to account for frequency content, while Arias Intensity (Arias, 1970) reflects all the characteristics (Kramer, 1996).

Attenuation relations are used in the Probabilistic Seismic Hazard Analysis (PSHA) to determine the seismic hazard at a given site, taking into account a number of factors like seismic sources model, attenuation law and the uncertainties in the model parameters. Usually the results of PSHA are hazard maps showing the ground motion level that will not be exceeded in a given time lag, with a given probability. Other ground motion measures of engineering significance derived from PSHA are the Uniform Hazard Spectra (UHS) and the ground motion time history (Naeim and Lew, 1995; Bommer et al., 2000). In this study, we will focus on the derivation of the ground motion attenuation relationships and will compare our results with other predictive relations already used in Italy.

\section{Ground-motion data}

The strong ground motions available for the Umbria-Marche area, Central Italy, include records provided by several Italian institutions, namely Servizio Sismico Nazionale (SSN), Ente Nazionale per l'Energia Elettrica (ENEL, now SOGIN) and Ente per le Nuove Tecnologie, l'Energia e l'Ambiente (ENEA), which are all available in digital format (SSN and ENEL, 1998; Imperial College et al., 2000). For this study, we used data from events occurred at different times: Norcia-Valnerina earthquake in 1979, Gubbio earthquake in 1984 and the 19971998 Umbria-Marche earthquakes. All these earthquakes were generated by normal or oblique faults parallel to the Apennine at focal depth ranging between 2.0 and $8.7 \mathrm{~km}$ (table I). The parameters listed in table I are derived from Deschamps et al. (1984) for Norcia-Valnerina earthquake, Haessler et al. (1988) for Gubbio earthquake and Cattaneo et al. (2000) for the 1997-1998 Umbria-Marche earthquakes.

Among all the data available for this area, we selected only the records produced by events

Table I. List of the Umbria-Marche, Central Italy, earthquakes used in this study.

\begin{tabular}{cccccccc}
\hline \hline Earthquake name & Date & Time & Latitude & Longitude & $M_{L}$ & Depth & N. records \\
\hline Norcia-Valnerina & 19.09 .79 & $21: 35$ & $42 \mathrm{~N} 43.80$ & $12 \mathrm{E} 57.60$ & 5.9 & 6.0 & 7 \\
Gubbio & 29.04 .84 & $05: 02$ & $43 \mathrm{~N} 15.00$ & $12 \mathrm{E} 31.20$ & 5.2 & 7.0 & 7 \\
Umbria-Marche & 03.09 .97 & $22: 07$ & $43 \mathrm{~N} 00.92$ & $12 \mathrm{E} 52.77$ & 4.5 & 8.7 & 1 \\
Umbria-Marche & 26.09 .97 & $00: 33$ & $43 \mathrm{~N} 01.24$ & $12 \mathrm{E} 50.83$ & 5.6 & 3.8 & 15 \\
Umbria-Marche & 26.09 .97 & $09: 40$ & $43 \mathrm{~N} 01.41$ & $12 \mathrm{E} 50.83$ & 5.9 & 6.5 & 21 \\
Umbria-Marche & 03.10 .97 & $08: 55$ & $43 \mathrm{~N} 02.05$ & $12 \mathrm{E} 50.52$ & 5.4 & 5.7 & 11 \\
Umbria-Marche & 04.10 .97 & $16: 13$ & $42 \mathrm{~N} 55.96$ & $12 \mathrm{E} 56.14$ & 4.8 & 2.1 & 5 \\
Umbria-Marche & 06.10 .97 & $23: 24$ & $43 \mathrm{~N} 00.91$ & $12 \mathrm{E} 50.58$ & 5.5 & 7.0 & 20 \\
Umbria-Marche & 12.10 .97 & $11: 08$ & $42 \mathrm{~N} 54.64$ & $12 \mathrm{E} 56.99$ & 5.3 & 2.2 & 10 \\
Umbria-Marche & 14.10 .97 & $15: 23$ & $42 \mathrm{~N} 54.91$ & $12 \mathrm{E} 55.77$ & 5.6 & 4.9 & 28 \\
Umbria-Marche & 16.10 .97 & $12: 00$ & $43 \mathrm{~N} 02.06$ & $12 \mathrm{E} 53.42$ & 4.6 & 2.0 & 7 \\
Umbria-Marche & 09.11 .97 & $19: 07$ & $42 \mathrm{~N} 51.26$ & $12 \mathrm{E} 59.99$ & 4.9 & 2.0 & 8 \\
Umbria-Marche & 21.03 .98 & $16: 45$ & $42 \mathrm{~N} 57.09$ & $12 \mathrm{E} 54.86$ & 4.6 & 4.1 & 6 \\
Umbria-Marche & 03.04 .98 & $07: 26$ & $43 \mathrm{~N} 11.05$ & $12 \mathrm{E} 45.54$ & 5.0 & 2.6 & 9 \\
Umbria-Marche & 05.04 .98 & $15: 52$ & $43 \mathrm{~N} 11.41$ & $12 \mathrm{E} 46.35$ & 4.7 & 5.4 & 6 \\
\hline
\end{tabular}




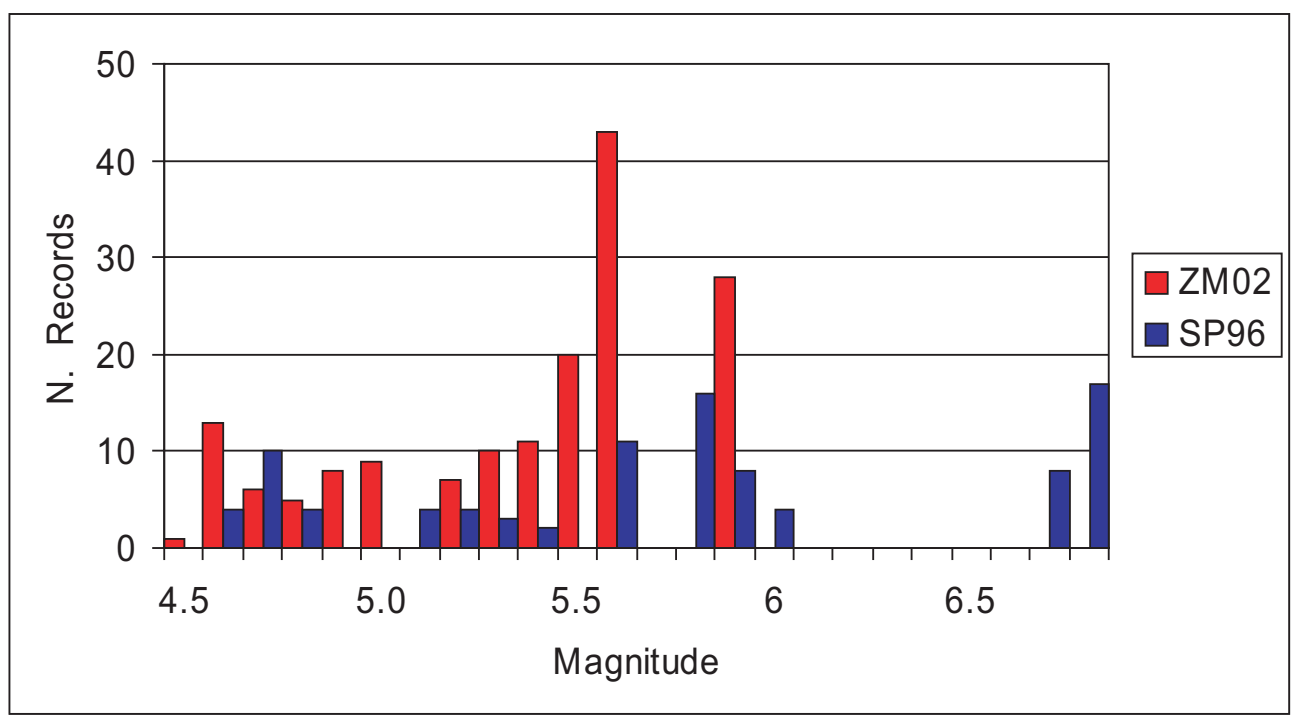

Fig. 1. The histogram shows the number of data used in this study (ZM02) and in SP96 for each magnitude level. Data for SP96 are obtained from Sabetta and Pugliese (1987).

with local magnitude $M_{t}$ bigger than 4.5 , recorded at less than $100 \mathrm{~km}$ of distance from the epicenter (fig. 2 and table I). The records of March 26th $1998, M_{L} 5.6$ earthquake were not considered in the analysis because this event occurred at $47 \mathrm{~km}$ depth; moreover, we did not use the records from the station of Nocera Umbra because it shows a strong amplification effect due to the presence of a sub-vertical fault and to highly fractured rocks (Marra et al., 2000).

The data set used for this study was therefore reduced to 161 records (see table I and fig. 1) whose horizontal components have been uniformly corrected using the software BAP (Basic strong motion Accelerogram Processing software; Converse and Brady, 1992). All the records, sampled with a $0.005 \mathrm{~s}$ interval (200 samples/s), were baseline and instrument corrected and then band-pass filtered applying a high-cut filter between 23 and $28 \mathrm{~Hz}$ and a low-cut filter represented by a bi-directional Butterworth filter with corner frequency of $0.4 \mathrm{~Hz}$ and rolloff parameter equal to 2 .

Since the largest earthquake in the data set turned out to be 26th September, $1997 M_{L} 5.9$ earthquake (see table I), in this study we are allowed to use local magnitude because this scale is known to saturate at about magnitude 6.5 (Lay and Wallace, 1995). Sabetta and Pugliese (1996) used $M_{L}$ for small magnitudes, and $M_{S}$ when both $M_{S}$ and $M_{L}$ were larger than 5.5. According to the relation derived by Rebez and Stucchi (1996) for Italy, the difference between $M_{S}$ and $M_{L}$, in the range of magnitude considered in this study, is sufficiently small to allow the comparison of the two analysed attenuation relationships. Also, Bolt (1989) suggests that for shallow earthquakes, as in our case study, $M_{L}$ scale should be used for magnitudes from 3 to 7 .

In this study, all the stations are classified as either rock or soil (as in Spudich et al., 1999), according to the superficial geology. The criterion used to define rock sites is the same as adopted in Ambraseys et al. (1996) and in Imperial College et al. (2000), and follows the scheme proposed by Boore et al. (1993) based on the measured or estimated average shear-wave travel-time velocity to a depth of $30 \mathrm{~m}$. According to this classification rock sites are characterized by shear-wave velocity larger than $750 \mathrm{~m} / \mathrm{s}$. The sites classified as stiff or soft soils (having respectively velocity between 360 and $750 \mathrm{~m} / \mathrm{s}$ and smaller than $360 \mathrm{~m} / \mathrm{s}$ ) are put 


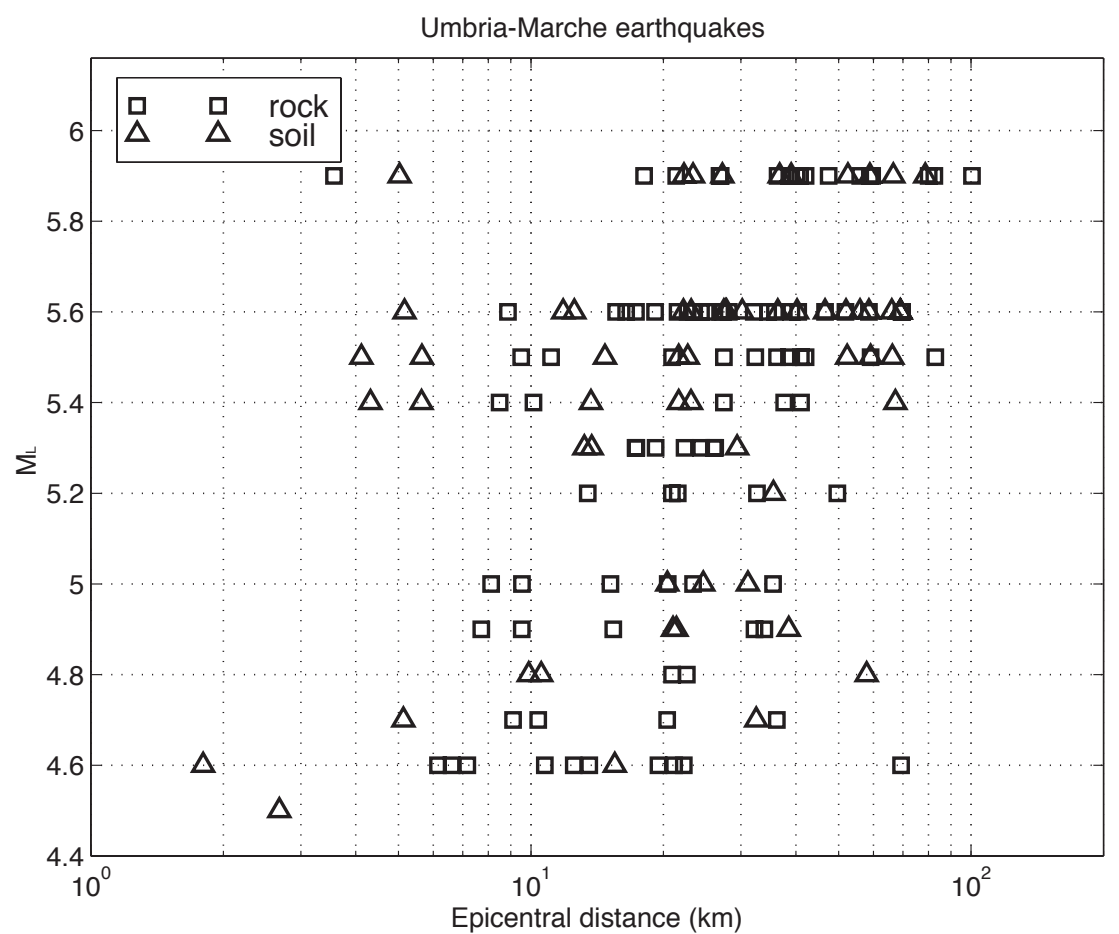

Fig. 2. Distribution of the records used in this study with respect to local magnitude $M_{L}$, epicentral distance $R$ $(\mathrm{km})$ and site geology.

together in a single class generically defined as «soil» (see table II). Sabetta and Pugliese (1996) used a different classification based on geological and geotechnical information including the depth of the sediments, so for these authors rock sites are located on outcrops, stiff shallow soils have average shear-wave velocity greater than $800 \mathrm{~m} / \mathrm{s}$ and are less than $20 \mathrm{~m}$ thick, while deep alluvium soils have thickness of more than $20 \mathrm{~m}$ and shear-wave velocity ranging between 400 and $800 \mathrm{~m} / \mathrm{s}$ (see table II).

Some problems may arise when comparing our results with SP96's because we did not consider the thickness of the soil. As shown in table II, according only to shear-wave velocity our «soil» class corresponds to SP96's «deep soil» class (see also fig. 6a,b), while the «shallow soil» class used by SP96 should correspond to «rock» for ZM02. This is proved not to be true by fig. 6a,b, showing that SP96's «shallow soil» pseudo-velocity response spectrum has a peak at high frequencies. Therefore we compared our «rock» curves with SP96 «rock» curves, when sites are defined as rock according to the classification by Ambraseys et al. (1996) and in Imperial College et al. (2000), while we suggest comparing SP96 «deep soil» curve with our «soil» curve for all the other cases.

For each horizontal acceleration recording we calculated peak ground acceleration (in $g$ ), peak ground velocity (in $\mathrm{cm} / \mathrm{s}$ ), Arias Intensity $\left(\mathrm{cm}^{2} / \mathrm{s}^{3}\right)$ and the pseudo-spectra of velocity (in $\mathrm{cm} / \mathrm{s}$ ) using a 5\% damping and then regression analysis was performed to evaluate the attenuation function for each of these indicators. The next paragraph discusses the methodology adopted for the regression analysis. 
Table II. Correlation between different soil classifications used for attenuation relationships.

\begin{tabular}{c|c|c|c}
\hline \hline ZM02 & Rock & \multicolumn{2}{|c}{ Soil } \\
& $V_{S 30}>750 \mathrm{~m} / \mathrm{s}$ & \multicolumn{2}{|c}{$V_{S 30} \leq 750 \mathrm{~m} / \mathrm{s}$} \\
\hline \multirow{2}{*}{ AMB96 } & Rock & Stiff soil & Soft soil \\
& $V_{S 30}>750 \mathrm{~m} / \mathrm{s}$ & $360 \leq V_{S 30} \leq 750 \mathrm{~m} / \mathrm{s}$ & $V_{S 30}<360 \mathrm{~m} / \mathrm{s}$ \\
\hline \multirow{2}{*}{ SP96 } & Rock & Shallow soil $(\mathrm{H} \leq 20 \mathrm{~mm})$ & Deep soil $(\mathrm{H}>20 \mathrm{~m})$ \\
& Outcrop & $V_{s}>800 \mathrm{~m} / \mathrm{s}$ & $400 \leq V_{s} \leq 800 \mathrm{~m} / \mathrm{s}$ \\
\hline
\end{tabular}

\section{Predictive equation}

Many predictive relationships derived from regression analysis of strong motion data are available in literature for horizontal peak acceleration, velocity and response spectral values. Several papers (for example, Campbell, 1985; Joyner and Boore, 1988) offer a review of the most commonly used equations and regression techniques: the general form chosen by most investigators to model attenuation is given by the following expression:

$$
f(Y)=a+f_{1}(M)+f_{2}(R)+f_{3}(S) \pm \sigma
$$

where $Y$ is the strong motion parameter to be predicted, $a$ is a coefficient that depends on frequency, $f_{1}(M)$ is a function of magnitude, $f_{2}(R)$ is a function of distance, $f_{3}(S)$ accounts for soil conditions and $\sigma$ is the standard deviation of $Y$.

As said in Section 1, the most recent attenuation relationships for Italy were calculated by Sabetta and Pugliese (1996), from a data set of 95 three components accelerometric recordings, generated by 17 Italian earthquakes of magnitude ranging from 4.6 to 6.8 and distances up to $100 \mathrm{~km}$.

This relation is generally used for the whole national territory, and its final form is the following equation:

$$
\begin{gathered}
\log _{10}(Y)= \\
=a+b M+c \log _{10}\left(R^{2}+h^{2}\right)^{1 / 2}+e_{1} S_{1}+e_{2} S_{2} \pm \sigma
\end{gathered}
$$

where $a$ is the offset term, $b$ is the magnitude term, and $c$ is the distance term, $M$ is the magnitude ( $M_{L}$ or $M_{S}$, as described previously), $R$ is the distance (fault or epicentral) in kilometers and $h$ is the pseudo-depth determined by regression that accounts for all the factors that tend to limit or reduce the motion near the source and also includes any factors that tend to enhance the motion near the source, like directivity (Joyner and Boore, 1981).

The terms $e_{1} S_{1}$ and $e_{2} S_{2}$ are related to the site classification ( $e_{1} S_{1}$ is for shallow soils, while $e_{2} S_{2}$ is for deep soils), and $\sigma$ is the standard deviation of the logarithm of $Y$. The values of the coefficients in eq. (3.2) were estimated through nonlinear multiple regression analysis, although it is worth noting that coefficient $c$ is set equal to -1 and does not vary because it represents the energy decay due to geometric spreading.

Another attenuation relationship often used in Italy is the one proposed by Ambraseys et al. (1996) that was calculated over a data set representative of European strong motions composed by 422 triaxial records generated by 157 earthquakes having magnitude $M_{S}$ between 4.0 and 7.9 and focal depth less than $30 \mathrm{~km}$. The equation adopted by these Authors has the following form:

$$
\begin{gathered}
\log _{10}(Y)=C_{1}+C_{2} M+C_{3} \log _{10}(r)+ \\
+C_{A} S_{A}+C_{S} S_{S}+\sigma P
\end{gathered}
$$

where $C_{1}$ is the offset term, $C_{2}$ is the magnitude term, $C_{3}$ is the distance term, $M$ is the magnitude $M_{s}$, and $r$ is the distance calculated as in eq. (3.2). The coefficient $C_{A} S_{A}$ accounts for stiff soils, while 
$C_{s} S_{s}$ is for soft soils, $\sigma$ is the standard deviation of the logarithm of $Y$, and $P$ is a coefficient that can take only the values 0 or 1 . Note that in the following paragraphs we will indicate the two cited papers and the relative attenuation relationships as SP96 and AMB96.

The attenuation relationship proposed in this paper is given by

$$
\begin{gathered}
\log _{10}(Y)=a+b M+ \\
+c \log _{10}\left(R^{2}+h^{2}\right)^{1 / 2}+e \Gamma \pm \sigma
\end{gathered}
$$

where $M$ is local magnitude $\left(M_{L}\right), R$ is epicentral distance in kilometers, $h$ is the pseudo-depth determined by regression, the coefficient $e$ accounts for soil condition, $\Gamma$ is a dummy variable that can take only the value 0 (for rock sites) or 1 (for soil sites) as in SEA99 (Spudich et al., 1999), and $\sigma$ is the standard deviation of the logarithm of $Y$.
The coefficients were calculated using a multiple step regression analysis, similar to the two-step procedure described by Joyner and Boore (1981), in which $a$ and $b$ are derived by linear regression for a given value of $h$, which is then determined, along with $c$, minimizing the sum of the squared residuals. After the twostage regression, the site coefficient was determined minimizing the residuals (see Ambraseys et al.,1996).

\section{Predicted horizontal response spectra}

We solved eq. (3.4) for $Y$ corresponding to the average of the horizontal Pseudo-Spectra of Velocity (PSV) calculated with 5\% damping (in $\mathrm{cm} / \mathrm{s}$ ), and the regression analysis described in the previous paragraph was performed on the data frequency-by-frequency for a total of 14 frequencies in the range between 0.25 and $25 \mathrm{~Hz}$.

Table III. Regression coefficients for eq. (3.2) for $Y$ equal to PSV, PGA, PGV or Arias Intensity. Coefficients are to be used for $4.5 \leq M_{L} \leq 5.9$ and epicentral distance $R \leq 100 \mathrm{~km}$.

\begin{tabular}{ccccccc}
\hline \hline Frequency $(\mathrm{Hz})$ & $a$ & $b$ & $c$ & $h$ & $e$ & $\sigma$ \\
\hline 0.25 & -3.002 & 0.773 & -1 & 2.1 & 0.157 & 0.329 \\
0.33 & -3.012 & 0.809 & -1 & 3.5 & 0.171 & 0.331 \\
0.50 & -3.169 & 0.890 & -1 & 5.5 & 0.243 & 0.348 \\
0.67 & -2.900 & 0.852 & -1 & 4.6 & 0.336 & 0.350 \\
1.00 & -2.280 & 0.745 & -1 & 4.9 & 0.292 & 0.319 \\
1.33 & -2.067 & 0.715 & -1 & 4.6 & 0.230 & 0.308 \\
2.00 & -1.608 & 0.635 & -1 & 3.1 & 0.101 & 0.295 \\
2.50 & -1.373 & 0.595 & -1 & 2.0 & 0.065 & 0.297 \\
3.33 & -0.878 & 0.505 & -1 & 2.1 & 0 & 0.288 \\
5.00 & -0.391 & 0.411 & -1 & 3.3 & 0 & 0.270 \\
6.67 & 0.038 & 0.310 & -1 & 3.2 & 0 & 0.269 \\
10.00 & 0.194 & 0.225 & -1 & 3.6 & 0 & 0.269 \\
15.00 & -0.036 & 0.225 & -1 & 3.1 & 0 & 0.274 \\
25.00 & -0.737 & 0.292 & -1 & 2.8 & 0 & 0.274 \\
\hline $\mathrm{PGA}(\mathrm{g})$ & -1.632 & 0.304 & -1 & 2.7 & 0 & 0.275 \\
\hline $\mathrm{PGV}(\mathrm{cm} / \mathrm{s})$ & -1.275 & 0.458 & -1 & 1.9 & 0.051 & 0.289 \\
\hline$I_{A}\left(\mathrm{~cm} / \mathrm{s}^{3}\right)$ & 0.713 & 0.664 & -1.046 & 0 & 0.075 & 0.335 \\
\hline
\end{tabular}



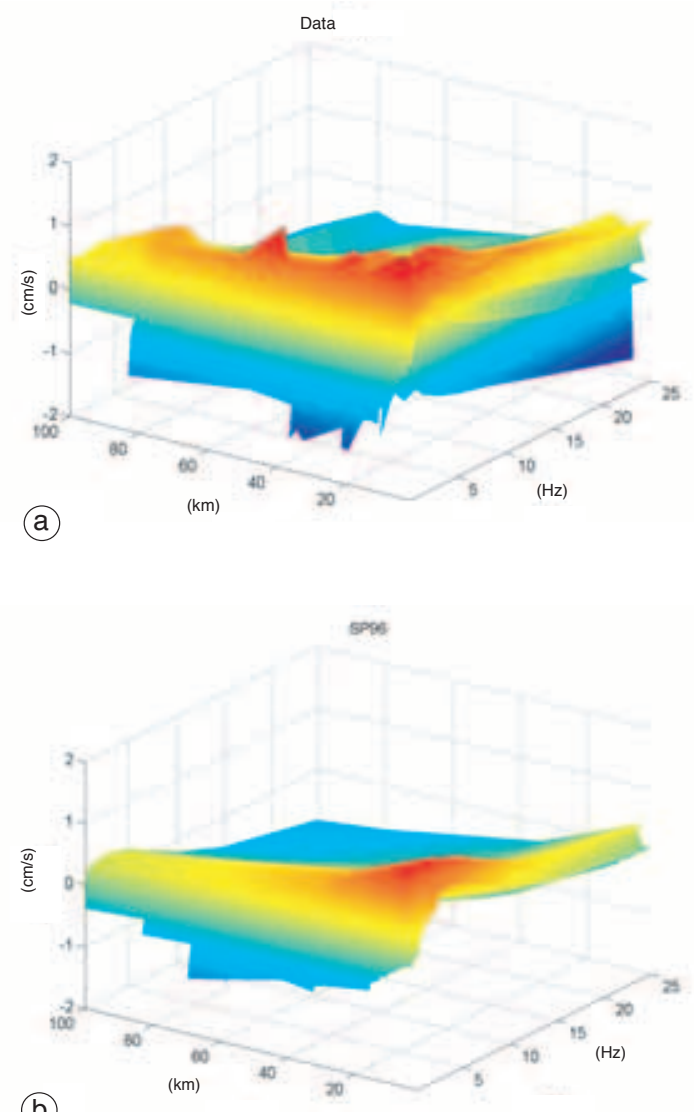

(b)

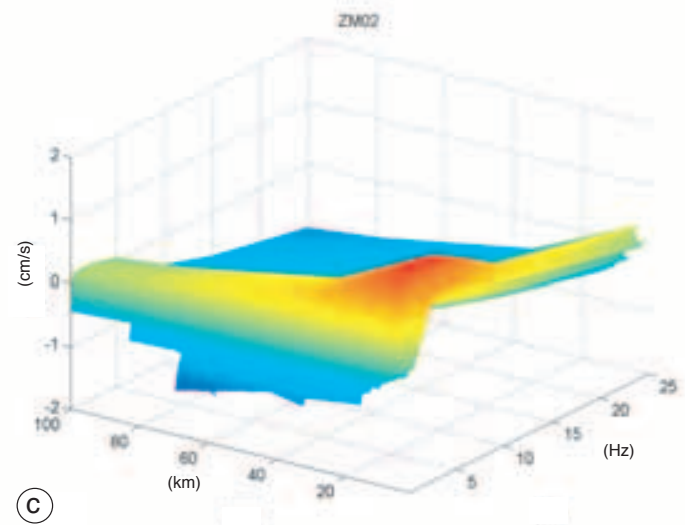

Fig. 3a-c. Comparison between PSV calculated from the data set (a) and two different attenuation functions: SP96 (b) and this study (ZM02 (c)).
The coefficients evaluated with our regression analysis are shown in table III, along with the corresponding frequencies.

Figure 3a-c compares the spectral values (PSV) of the data (fig. 3a) and the results of different attenuation functions: SP96 (fig. 3b) and this study (indicated by ZM02, fig. 3c). In each plot, the horizontal axes are frequency (in $\mathrm{Hz}$ ) and epicentral distance (in $\mathrm{km}$ ), while colors indicate different values of the logarithm of PSV. These figures show that our attenuation function reproduces the same upper values of SP96 but it decays faster as distance increases. This result is due to the small amplitudes shown by our data at large distances (see fig. 2): in fact we have records from small, shallow events which have very small amplitude at large distance, while SP96 data are generated by strong events (magnitude larger than 5.5 and up to 6.8) and therefore they have larger amplitudes at the same distances.

Generally, the results of regression analysis are of good quality, as proved by relatively small standard deviations. Figure $4 a, b$ shows two examples of good quality of fit between recorded and simulated spectra. The first (in fig. 4a) was recorded during 26th September 1997, $M_{L}=5.6$ earthquake at Cascia, which is a rock site (Imperial College et al., 2000) located at about $35 \mathrm{~km}$ from the epicenter on calcareous marl aged Paleogene (SSN and ENEL, 1998). The second example (fig. 4b) is a record of October 14th 1997, $M_{L}=5.6$ earthquake at the site of Spoleto Monteluco. This station is located at about $30 \mathrm{~km}$ from the epicenter on massif Jurassic limestone (SSN and ENEL, 1998), therefore is classified as rock (Imperial College et al., 2000). In each plot, the black solid curve is the average horizontal component of the spectrum, our results are in red, while SP96 is in blue. The figure shows that SP96 curves fit the higher values of the spectra calculated from the data, while ZM02 seems to be smoothing the data.

Figure 5a shows the spectra calculated at different epicentral distances $(5,10,30,50,100$ and $200 \mathrm{~km}$ ) for a fixed value of local magnitude $\left(M_{L}=6\right)$ and fixed site geology (rock). All the curves have the same shape, characterized by a plateau between 0.50 and $5.0 \mathrm{~Hz}$, and amplitudes decrease with increasing distance. Figure $5 \mathrm{~b}$ 

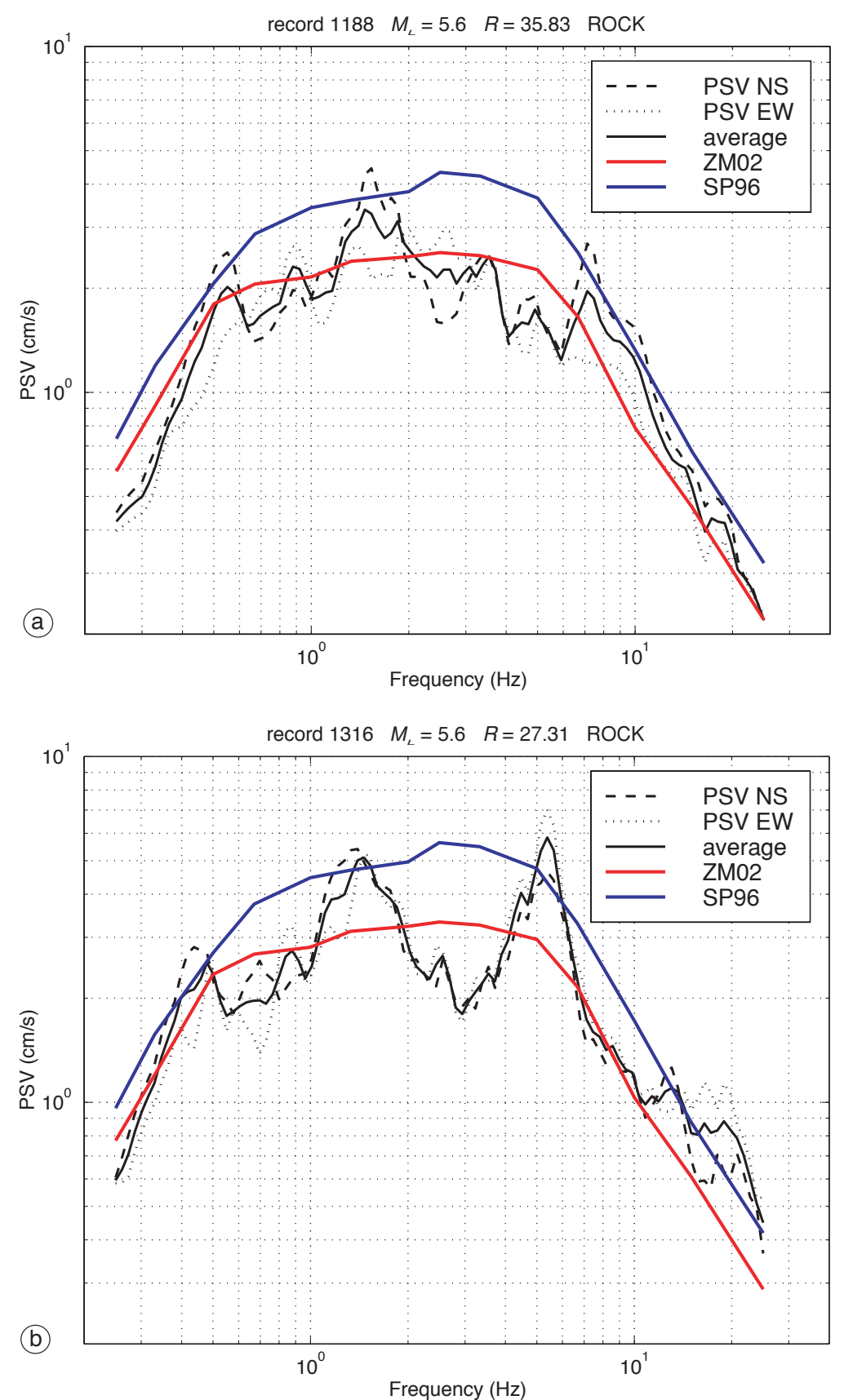

Fig. 4a,b. Comparison between PSV derived from processed records (black curves) and PSV calculated using ZM02 (red curve) and SP96 (blue curve). Figure 4a shows the case of RA01188 recorded at the site of Cascia during 26th September 1997, $M_{L}=5.6$ earthquake; in fig. $4 \mathrm{~b}$ the case of RA01316, recorded of Spoleto Monteluco during 14th October 1997, $M_{L}=5.6$ earthquake. 

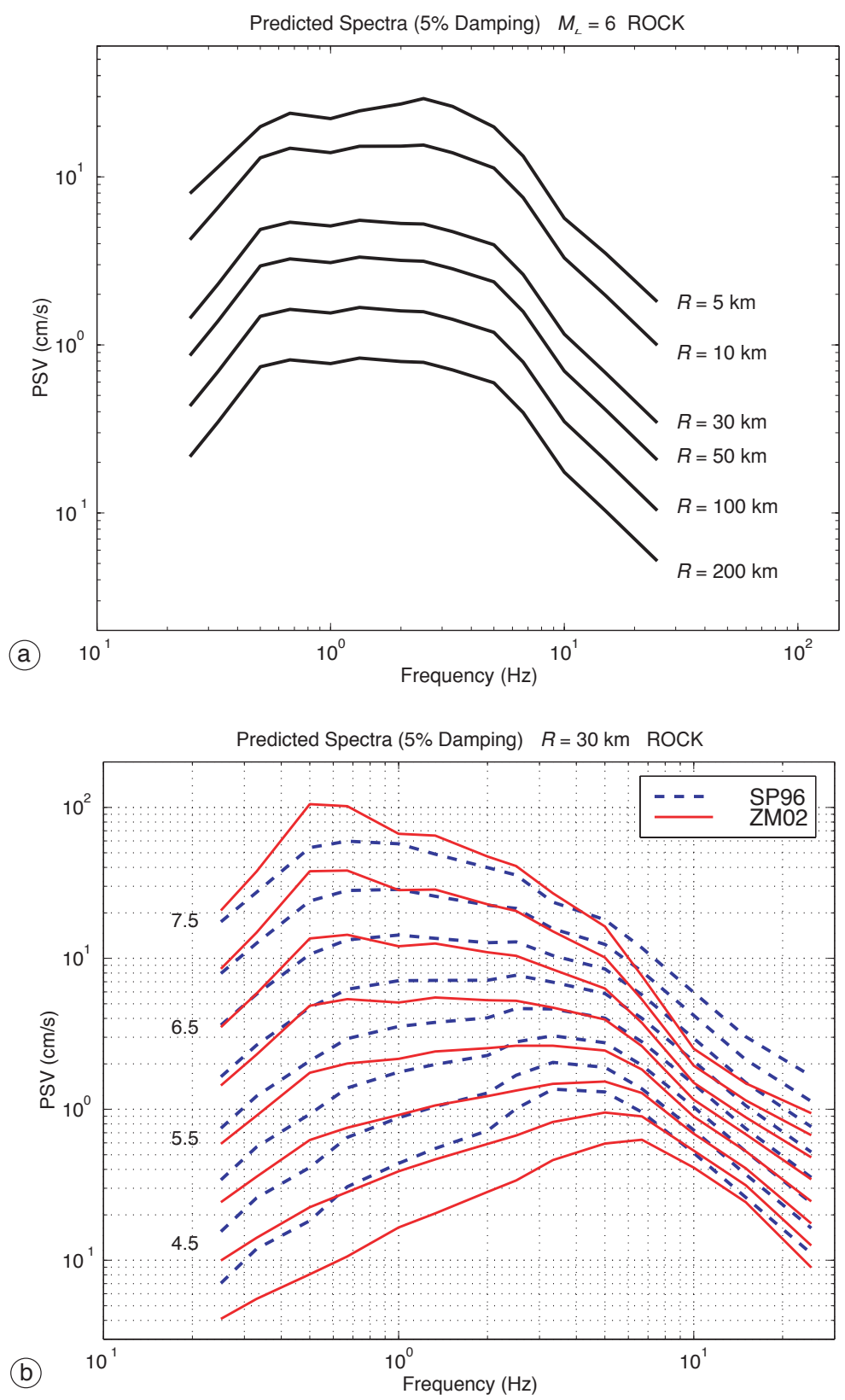

Fig. 5a,b. Figure 5a shows the predicted (5\% damping) PSV curves versus the frequency for different values of the epicentral distance (i.e. $R=5,10,30,50,100$ and $200 \mathrm{~km}$ ) calculated with the attenuation relations proposed by this study (see table III) for a rock site and local magnitude $M_{L}=6$. Figure $5 \mathrm{~b}$ shows a comparison of the predicted (5\% damping) PSV versus the frequency for a fixed epicentral distance $(R=30 \mathrm{~km})$ and at different levels of local magnitude (i.e. $M_{L}$ ranging between 4 and 7.5, each step is equal to 0.5). The red lines are relative to the results of this study (ZM02) while the blue dashed curves are SP96 (raw curves). 
shows the comparison between the pseudospectra of velocity calculated at a fixed epicentral distance $(R=30 \mathrm{~km})$ for eight values of local magnitude (from $M_{L}=4$ to $M_{L}=7.5$ with a 0.5 step) at rock sites. The results deduced by this study are in red, while the spectra by SP96 are represented by blue dashed lines. It is interesting that the two attenuation relationships give very different results both at small and large frequencies. In fact up to $M_{L}=5.5 \mathrm{SP} 96$ is systematically higher than our results at the small frequencies; while for higher magnitudes the opposite situation occurs. For large frequencies (above $5 \mathrm{~Hz}$ ), SP96 is always larger than our curves. Figure 5a,b (for rock sites) shows the predictive values of the two attenuation relationships computed outside their theoretical limits of magnitude and distance, although it is common practice in PSHA to perform the analysis for magnitudes ranging between 4 and 7 and for distances up to $200 \mathrm{~km}$.

To explain these discrepancies on the results one might claim different facts: first of all, and most important, the different data set used. It is clear from fig. 1 that more than $50 \%$ of our records are from events with local magnitude $M_{L}$ smaller or equal to 5.5, while most of Sabetta and Pugliese (1996) data (nearly two thirds) are larger than that. As a consequence, small or intermediate magnitudes have more weight in our attenuation functions compared to SP96, thus providing smaller values of the ground motion. As a general statement, the attenuation function proposed in this study should not be used for $M_{L}$ greater than 6 since such magnitudes are not present in our data set, while SP96 can be extended more confidently toward large events because some records of magnitude 6.8 are included in their analysis.

We can also attribute some differences to the fact that we used the average of the two horizontal components instead of the larger of the two (as SP96) and thus we have introduced some sort of smoothing in the data, eventually lowering high values.

Finally we recall the slightly different bandpass filtering frequencies used in our study (see Section 2) compared to SP96. These authors used cutoff frequencies for the high-cut filter ranging between 0.2 and $0.7 \mathrm{~Hz}$, with typical values of
0.3 , and ranging between 23 and $35 \mathrm{~Hz}$ for the low-cut filter, with typical values of $25 \mathrm{~Hz}$.

The different soil classification adopted in this study and in SP96 has been discussed previously (Section 2). Figure 6a represents the predicted response spectra calculated with ZM02 attenuation relationship for the soil categories explained in table II, while fig. $6 \mathrm{~b}$ presents the results for SP96. If we compare fig. $6 a$ and b, it is immediately noted that the soil class used in this study (dashed line in fig. 6a) is more similar to the deep soil class used by SP96 (dashed line in fig. 6b). The maximum value reached by the two curves is approximately the same (about 12 $\mathrm{cm} / \mathrm{s}$ ), but ZM02's peak occurs at $0.7 \mathrm{~Hz}$, while SP96 reaches the maximum at about $1.2 \mathrm{~Hz}$.

Some useful indicators of the strong motion's spectral energy are the Response Spectrum Intensity (SI, Housner, 1959) and the Acceleration Spectrum Intensity (ASI, Von Thun et al., 1988), that represent the response spectrum ordinates in period ranges of engineering significance and are defined as follows:

$$
\begin{gathered}
S I(\xi)=\int_{0.1}^{2.5} \operatorname{PSV}(\xi, T) \cdot d T \\
A S I=\int_{0.1}^{0.5} S_{a}(\xi=0.05, T) \cdot d T
\end{gathered}
$$

where $\xi$ is the damping and $T$ is the period. These parameters were calculated from the PSV obtained with SP96 and ZM02 attenuation functions for a rock site and different magnitudedistance levels (see tables IV and V; the numbers in italic refer to SP96). As expected from figs. 4a,b and 5b, ZM02 outcomes are smaller than SP96 results because our predicted spectra have always smaller values up to $M_{L}=6$, but if we extend the calculation up to $M_{L}=7$, we obtain larger values of ASI for all distances and larger values of SI only for very small distances, and slightly smaller values elsewhere. Therefore, if used in PSHA, our attenuation relationship will give smaller values of the ground motion indicators compared to SP96 (thus decreasing the level of hazard) in those source zones characterized by low or moderate size earthquakes. 

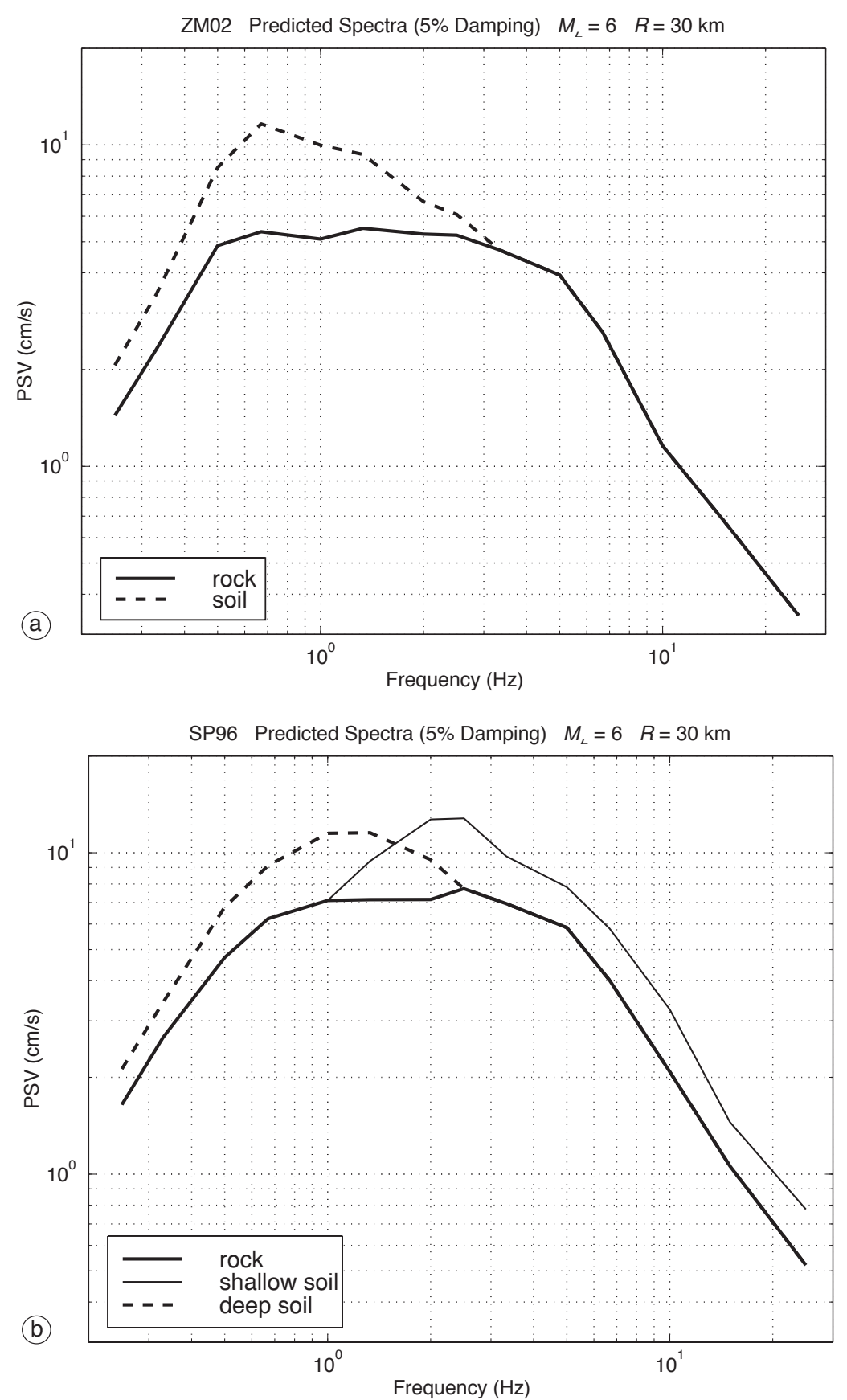

Fig. 6a,b. Predicted velocity response spectra for different soil classes. Figure 6a represents the results of this study for rock (thick solid line) and soil (dashed line); fig. 6b shows the results of SP96 for rock (thick solid line), shallow soil (thin solid line) and deep soil (dashed line). 
Table IV. Values of response spectrum intensity (SI, in $\mathrm{cm}$ ) for rock sites, using the PSV attenuation relationships ZM02 and SP96 (numbers in italics correspond to SP96).

\begin{tabular}{ccccccc}
\hline \hline SI $(\mathrm{cm})$ & \multicolumn{7}{c}{ Epicentral distance $(\mathrm{km})$} \\
\cline { 1 - 6 }$M_{L}$ & 5 & 10 & 30 & 50 & 100 & 200 \\
\cline { 2 - 7 } 4 & 5.66 & 3.21 & 1.12 & 0.67 & 0.34 & 0.17 \\
& 8.41 & 5.52 & 2.08 & 1.26 & 0.63 & 0.32 \\
\hline 5 & 13.89 & 7.84 & 2.73 & 1.65 & 0.82 & 0.41 \\
& 19.43 & 12.68 & 4.76 & 2.89 & 1.45 & 0.73 \\
\hline \multirow{2}{*}{6} & 38.91 & 22.00 & 7.68 & 4.63 & 2.32 & 1.16 \\
& 46.99 & 30.41 & 11.36 & 6.89 & 3.46 & 1.73 \\
\hline 7 & 127.64 & 72.84 & 25.55 & 15.40 & 7.71 & 3.86 \\
& 121.01 & 77.52 & 28.79 & 17.44 & 8.76 & 4.38 \\
\hline
\end{tabular}

Table V. Values of acceleration spectrum intensity (ASI, in $\mathrm{cm} / \mathrm{s}$ ) for rock sites, using the PSV attenuation relationships ZM02 and SP96 (numbers in italics correspond to SP96).

\begin{tabular}{ccccccc}
\hline \hline ASI $(\mathrm{cm} / \mathrm{s})$ & \multicolumn{7}{c}{ Epicentral distance $(\mathrm{km})$} \\
\cline { 1 - 6 }$M_{L}$ & 5 & 10 & 30 & 50 & 100 & 200 \\
\cline { 3 - 7 } & 8.48 & 5.09 & 1.83 & 1.10 & 0.55 & 0.28 \\
& 22.47 & 13.71 & 4.95 & 2.99 & 1.50 & 0.75 \\
\hline 5 & 46.15 & 27.93 & 10.06 & 6.08 & 3.05 & 1.52 \\
& 86.96 & 52.91 & 19.06 & 11.51 & 5.77 & 2.89 \\
\hline \multirow{2}{*}{6} & 260.98 & 159.09 & 57.45 & 34.71 & 17.41 & 8.71 \\
& 344.57 & 209.02 & 75.18 & 45.41 & 22.77 & 11.39 \\
\hline 7 & 1530.80 & 983.15 & 339.50 & 205.18 & 102.91 & 51.49 \\
& 1395.90 & 844.30 & 303.22 & 183.12 & 91.81 & 45.94 \\
\hline
\end{tabular}

\section{Predicted peak ground acceleration, velocity and Arias Intensity}

Several indicators may be used to characterize the ground motions for purposes of seismic design: these include peak acceleration, peak velocity, response spectral values and Fourier spectral values. Response spectral values were discussed in the previous paragraph, while peak ground acceleration, peak ground velocity and Arias Intensity will be analyzed in this section.

Peak Ground Acceleration (PGA) is defined as the largest absolute value of horizontal acceleration derived from each accelerogram. The PGA attenuation relationship proposed in this study is calculated by regression analysis using the approach described in Section 3. The dependent variable $Y$ in eq. (3.4) is the larger horizontal component of each record, and the coefficients $a, b, c, h$ and $e$ determined by regression are listed in table III.

The attenuation relationship obtained in this study always predicts lower PGA compared to AMB96, while compared to SP96 it gives higher PGA values only for small magnitudes and small distances. Figure 7 shows the three different attenuation functions and the data with magnitude $M_{L}=5.6$, plotted with different symbols according to the soil category (squares are for rock, circles for stiff soils, and triangles for soft soils). Figure 8 shows the same data, but the curves represented are the result of this study without standard deviation (solid red line), and 


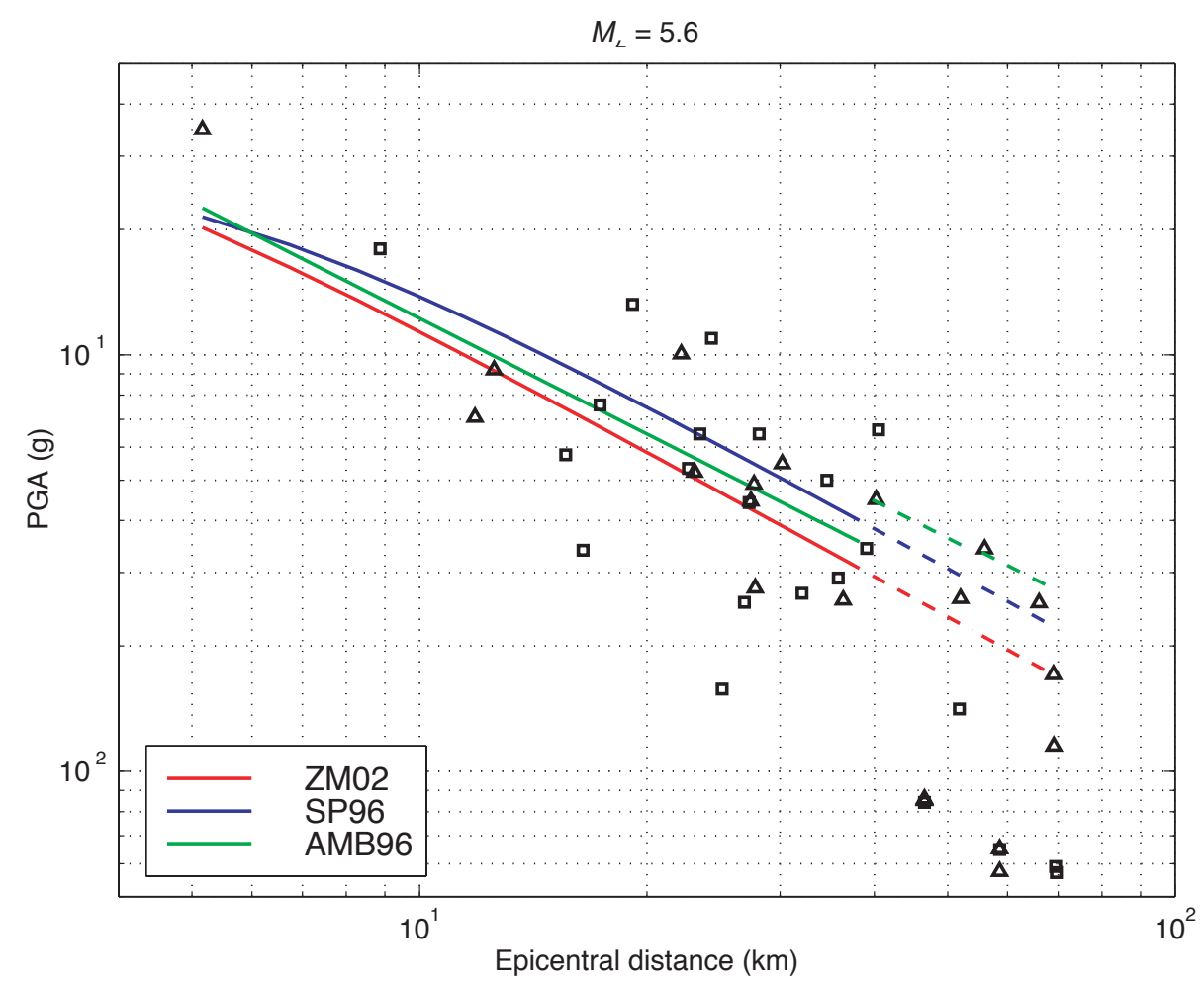

Fig. 7. Different PGA attenuation functions are plotted with respect to epicentral distance for local magnitude $M_{L}=5.6$. The red line is the curve calculated in this study (ZM02), in blue is SP96 attenuation relationship and in green is AMB96. Solid lines are for rock sites, while dashed lines are the attenuation relationships for soil. The black symbols represent all the data with $M_{L}=5.6$ : squares are for rock sites, triangles for soils (see table II).

introducing the standard deviation (summed or subtracted). When the standard deviation is considered in the analysis the majority of data are inside the curve plus or minus one standard deviation. Only a few data are slightly higher than the curve plus standard deviation and a few more data points are smaller than the curve minus standard deviation. The latter were recorded by digital instruments installed by Servizio Sismico Nazionale and show very small PGA because are located at large distance from the fault, near L'Aquila.

Another parameter used to quantify the amplitude of the ground motion is Peak Ground Velocity (PGV), which gives information particularly at intermediate frequencies. We derived PGV by integration of the accelerograms, and as for PGA, we used the larger value of the two horizontal components of each record to define the coefficients in the attenuation function (eq. (3.4)), and the results are listed in table III.

Finally, an attenuation function was derived for the Arias Intensity (Arias, 1970), whose coefficients are listed in table III (bottom line). The pseudo-depth $h$ calculated from regression analysis results equal to zero. In fact the values of Arias Intensity (in $\mathrm{cm}^{2} / \mathrm{s}^{3}$ ) are quite large and depend only on distance because the effect of $h$, which is always very small, is almost irrelevant. 


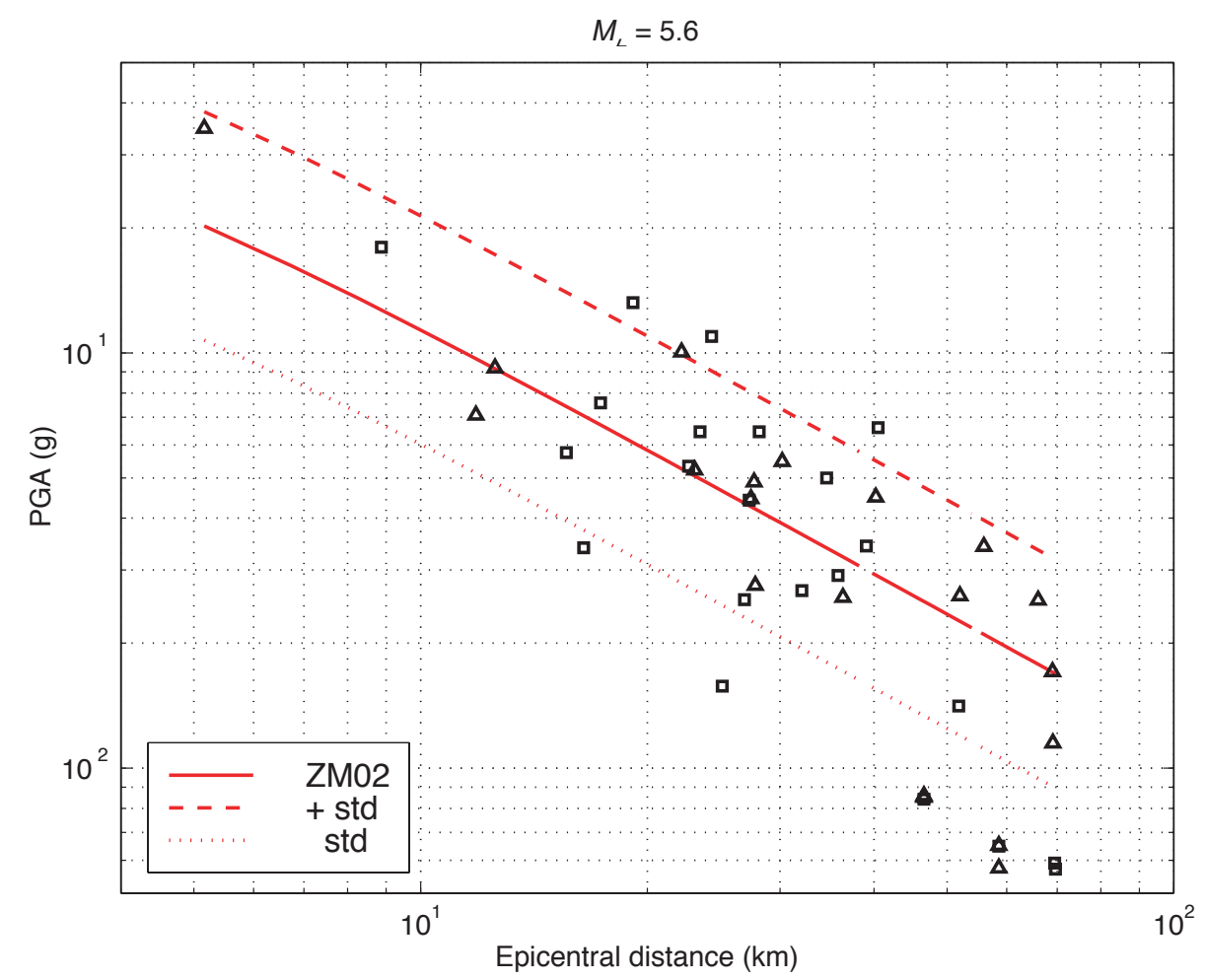

Fig. 8. Peak Ground Acceleration attenuation function is plotted with respect to epicentral distance for local magnitude $M_{L}=5.6$ (solid line), while the dashed and the dotted lines are respectively PGA attenuation relationship plus or minus one standard deviation. The black symbols represent the observed PGA: squares are for rock sites, triangles for soils (see table II).

\section{Conclusions}

This study aimed at refining Italian attenuation relationships at regional scale using a data set of 322 horizontal strong ground motions recorded in Umbria-Marche, Central Italy. The analysis was restricted to this area because the amount of records is now large enough to be statistically significant, thus overcoming one of the most common criticisms of attenuation relationships. The data set includes records generated by events with local magnitude $\left(M_{L}\right)$ ranging between 4.5 and 5.9 , and epicentral distance smaller than $100 \mathrm{~km}$, which represent the limits beyond which the attenuation functions should be used. Through a multiple steps regression analysis, we have calculated empirical equations for the peak ground acceleration and velocity, the Arias Intensity and for the horizontal components of the $5 \%$ damped velocity pseudo response spectra, corresponding to 14 frequencies ranging from 0.25 to $25 \mathrm{~Hz}$.

The attenuation relationships were tested comparing the results to other attenuation relations generally assumed to be valid for the whole national territory. The comparison with Sabetta and Pugliese (1996) results, in terms of PSV, shows that for small frequencies our curves are systematically smaller than SP96 up to $M_{L}=$ 6 , while for higher magnitudes this situation is inverted. For high frequencies our curves are always smaller than SP96 for all magnitudes. 
The use of indicators like SI and ASI helps understanding the response spectrum ordinates in period ranges of engineering significance and prove that SP96 outcomes are higher than ZM02 results for $M_{L} \leq 6$. In terms of PGA, the attenuation relationship obtained in this study gives higher values compared to SP96 only for small magnitudes and small distances.

These results are not surprising because we mostly used records from events with local magnitude $M_{L}$ smaller or equal to 5.5 , whereas only one third of Sabetta and Pugliese (1996) data belong to this range of magnitude. Also in this study the highest magnitude is equal to 5.9, while SP96 uses data up to 6.8. As a consequence, in our study small or intermediate magnitudes weigh more than large magnitudes, and this means that our attenuation functions will provide smaller values of each ground motion indicator.

\section{Acknowledgements}

This study was supported by the Istituto Nazionale di Geofisica e Vulcanologia in the framework of hazard and seismic risk topic studies. In particular we are grateful to Dr. Marco Cattaneo at INGV for providing useful data, and to an anonymous reviewer for fruitful comments.

\section{REFERENCES}

Ambraseys, N.N., K.A. SimPSON and J.J. BOMMER (1996): Prediction of horizontal response spectra in Europe, Earthquake Eng. Struct. Dyn., 25, 371-400.

ARIAS, A. (1970): A measure of earthquake intensity, in Seismic Design for Nuclear Power Plants, edited by R. HANSEN (MIT Press, Cambridge), 438-483.

BENDER, B. and D.M. PERKINS (1987): SEISRISK III: a computer program for seismic hazard estimation, U.S. Geol. Surv. Bull., 1772, pp. 48

BoLT, B.A. (1989): The nature of earthquake ground motion, in The Seismic Design Handbook, edited by F. NAEIM (Van Nostrand Reinhold, New York),1-31.

BOMMER, J.J., S.G. SCOTT and S.K. SARMA (2000): Hazardconsistent earthquake scenarios, Soil Dyn. Earthquake Eng., 19, 219-231.

Boore, D.M., W.B. JoYNer and T. FumaL (1993): Estimation of response spectra and peak acceleration from Western North American earthquakes: an interim report, U. S. Geol. Surv. Open-File Report 93-509.

CAMPBELL, K.W. (1985): Strong motion attenuation re- lations: a ten-year perspective, Earthquake Spectra, 1, 759-804.

Cattaneo, M., P. Augliera, G. De Luca, A. Gorini, A. Govoni, S. MARCUCCI, A. Michelini, G. MonACHESI, D. Spallarossa, L. TroJANI and XGUMS (2000): The 1997 Umbria-Marche (Italy) earthquake sequence: analysis of the data recorded by the local and temporary network, J. Seismol., 4, 401-414.

Converse, A.M. and A.G. Brady (1992): BAP: Basic Strong-Motion Accelerogram Processing Software, version 1.0, U. S. Geol. Surv. Open-File Rep. 92-296A.

Decanini, L., F. Mollaioli, G.F. Panza, F. Romanelli and F. VACCARI (2001): Probabilistic $v s$ deterministic evaluation of seismic hazard and damage earthquake scenarios: a general problem, particularly relevant for seismic isolation, in Proceedings of the 7 th International Seminar on Seismic Isolation, Passive Energy Dissipation and Active Control of Vibrations of Structures, Assisi, Italy, October 2-5, 2001, vol. 1, 117-141.

DEsChAMPS, A., G. IANNACCONE and R. SCARPA (1984): The Umbrian earthquake (Italy) of 19 September 1979, Ann. Geophys., 2, 29-36.

Haessler, H., R. Gaulon, L. Rivera, R. Console, M. Frogneux, G. Gasparini, L. Martel, G. Patau, M. SiCiliano and A. Cisternal (1988): The Perugia (Italy) earthquake of 29 April 1984: a microearthquake survey, Bull. Seismol. Soc. Am., 78, 1948-1964.

Housner, G.W (1959): Behavior of structures during earthquakes, ASCE J. Eng. Mech. Div., 85, N. EM14, 109-129.

IMPERial COLlege of SCIENCE, TECHNOLOGY AND MEDICINE, SOGIN-SSN, ENEA and IPSN (2000): European Strong-Motion Database, European Council, Environment and Climate Research Programme, CD-ROM.

JOYNER, W.B and D.M. BoORE (1981): Peak horizontal acceleration and velocity from strong-motion records including records from the 1979 Imperial Valley, California, earthquake. Bull. Seismol. Soc. Am., 71, 2011-2038.

JOYNER, W.B and D.M. BoORE (1988): Measurement, characterization and prediction of strong ground motion, in Earthquake Engineering and Soil Dynamics II - Recent Advance in Ground-Motion Evaluation, Geotechnical Special Publication 20, ASCE, New York, 463-481.

KRAMER, S.L. (1996): Geotechnical Earthquake Engineering (Prentice Hall), pp. 653.

LAY, T. and T.C. WALlACE (1995): Modern Global Seismology (Academic Press), pp. 521.

Marra, F., R. Azzara, F. Bellucci, A. Caserta, G. Cultrera, G. Mele, B. Palombo, A. Rovelli and E. BOSCHI (2000): Large amplification of ground motion at rock sites within a fault zone in Nocera Umbra (Central Italy), J. Seismol., 4, 543-554.

NAEIM, F. and M. LEW (1995): On the use of design spectrum compatible time histories, Earthquake Spectra, 11, 111-127.

REBEZ, A. and M. STUCCHI (1996): La determinazione della $M_{s}$ a partire da dati macrosismici per i terremoti 
compresi nei cataloghi NT, GNDT, Rapporto Interno, Trieste-Milano, pp. 48 (in Italian).

SabetTA, F. and A. PUGliese (1987): Attenuation of peak horizontal acceleration and velocity from Italian strongmotion records, Bull. Seismol. Soc. Am., 77, 1491-1513.

Sabetta, F. and A. Pugliese (1996): Estimation of response spectra and simulation of nonstationary earthquake ground motions, Bull. Seismol. Soc. Am. 86, 337-352.

SOMERVILlE, P. (2000): New developments in seismic hazard estimation, in Proceedings of the "Sixth International Conference on Seismic Zonation (6ICSZ)», Palm Springs, CA, 12-15 November 2000, CD-ROM.

SPudich, P., W.B. JoYNER, A.G. LindH, D.M. BOORE, B.M. MARGARIS and J.B. FleTCHER (1999): SEA99: a revised ground motion prediction relation for use in extensional tectonic regimes, Bull. Seismol. Soc. Am., 89, $1156-1170$

SSN and ENEL (1998): Elaborazione delle Principali Registrazioni Accelerometriche della Sequenza Sismica Umbro-Marchigiana del Settembre-Ottobre 1997, 3 vol. + CD-ROM, Roma, 21 maggio 1998 (in Italian)

Von Thun, J.L., L.H. RochiM, G.A. ScotT and J.A. WILSON (1988): Earthquake ground motion for design and analysis of dams, in Earthquake Engineering and Soil Dynamics II - Recent Advance in Ground-Motion Evaluation, Geotechnical Special Publicaton 20, ASCE, New York, 463-481.

(received September 5, 2001 accepted February 21, 2002) 